\title{
Testosterone therapy in female-to-male transsexuals: effects on gonadotropins, prolactin, gonadal steroids and menstrual cycle.
}

\author{
Martinez-Martin FJ*, Quintana-Arroyo S, Acosta-Socorro C, Arnas-Leon C, Santana-Suarez AD
}

Endocrinology Dpts, *Hospital San Roque and Hospital Dr. Negrin, Las Palmas de Gran Canaria, Spain
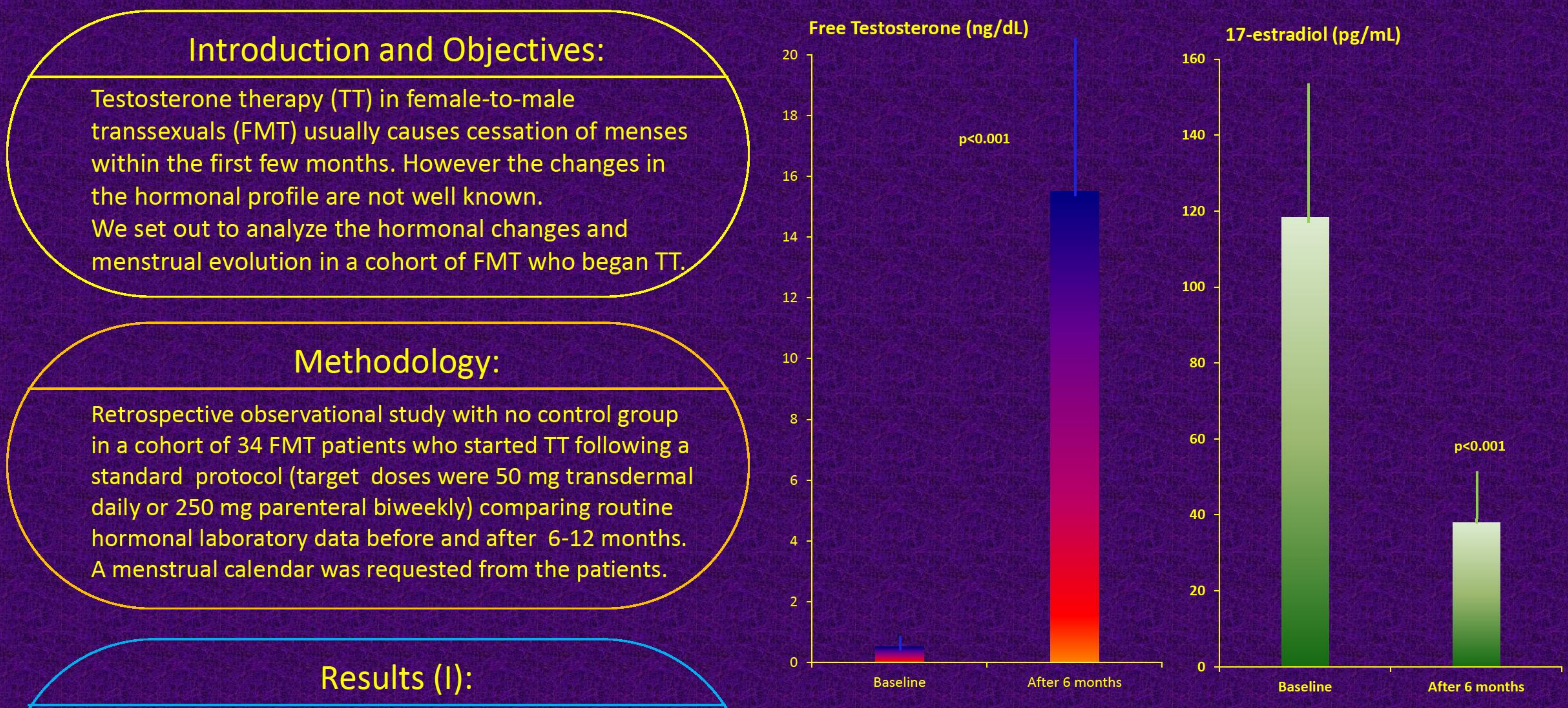

Age was $27 \pm 6$ years and BMl $26.7 \pm 3.1 \mathrm{~kg} / \mathrm{m} 2$ (mean \pm s.d.) As expected, treatment increased free testosterone $(0.51 \pm$ 0.18 to $15.5 \pm 5.2 \mathrm{ng} / \mathrm{dL}, \mathrm{p}<0.001$, paired t-test) and reduced 17 - $\beta$-estradiol $(118.3 \pm 39.4$ to $37.9 \pm 14.1 \mathrm{pg} / \mathrm{mL}, \mathrm{p}<0.001)$. $\mathrm{LH}$ and FSH were also reduced $(33.7 \pm 13.4$ to $1.7 \pm 0.7 \mathrm{mIU} / \mathrm{mL}$, and $9.9 \pm 4.5$ to $1.7 \pm 0.7 \mathrm{mIU} / \mathrm{mL}$, both $p<0.001$ ), while PRL was unchanged ( $16.6 \pm 6.8$ to $17.5 \pm 7.6 \mathrm{ng} / \mathrm{mL}, p=0.155)$.
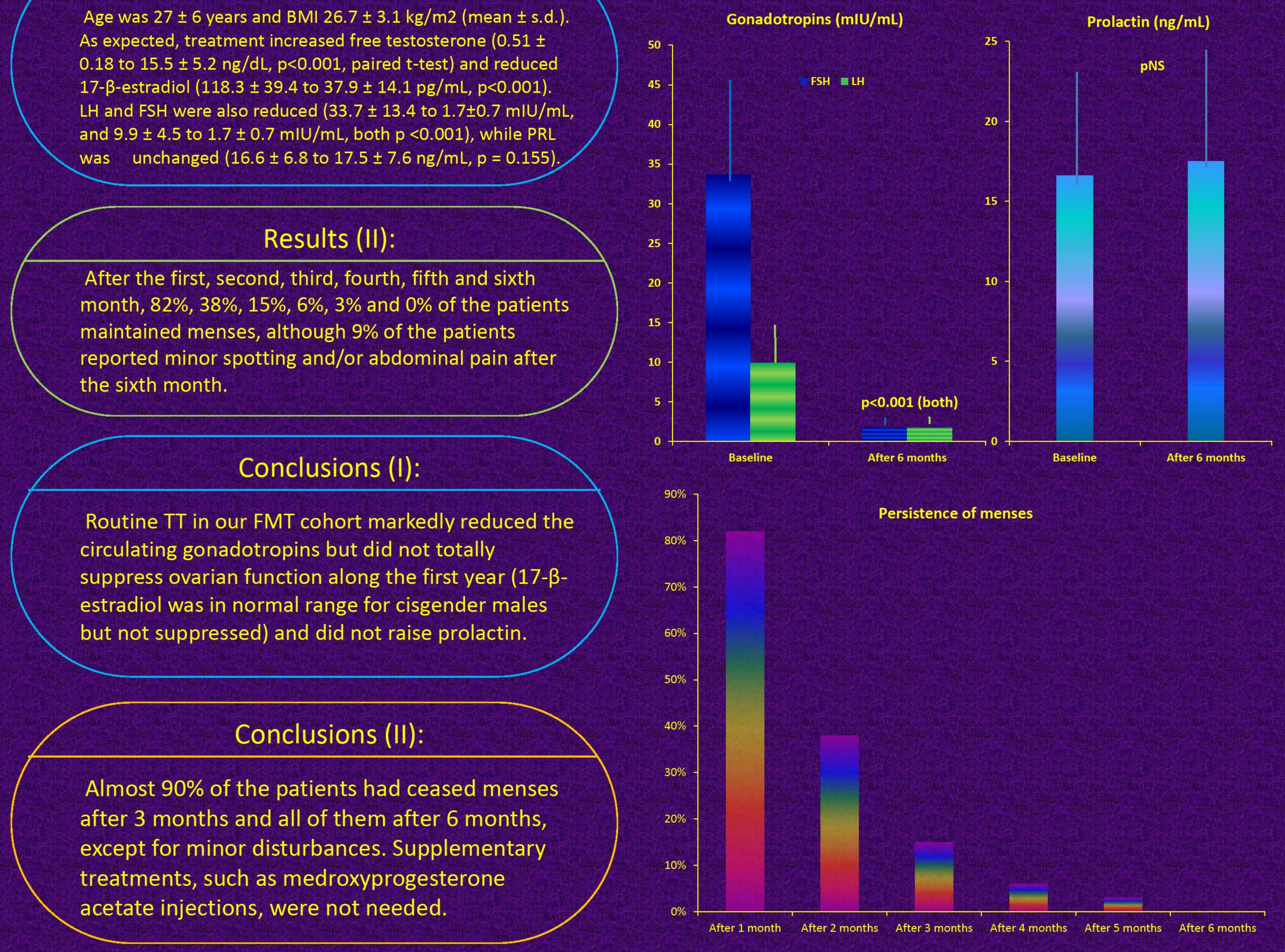